\title{
Ecological tourism public marketing: responses to grand challenges
}

\author{
Olena Uhodnikova ${ }^{1, *}$, Nataliia Bogdan ${ }^{1}$, Mariia Pokolodna ${ }^{1}$, Olha Radionova ${ }^{1}$, and \\ Kostiantyn Viatkin ${ }^{1}$ \\ ${ }^{1}$ O.M. Beketov National University of Urban Economy in Kharkiv, Department of Tourism and \\ Hospitality, Ukraine
}

\begin{abstract}
The paper is dedicated to some aspects of ecological tourism development. Under the conditions of revenue and tourist flow decrease because of the global quarantine restrictions, border closure and global downturn, as well as reduction in personal income, searching new ways of loss minimization is essential to the further development of travel industry. For this purpose, it is proposed to consider new travel offers, which can be on-trend under the conditions of a pandemic. Ecotourism can become such kind of tourism because of a wish of tourists to visit precisely natural objects under the conditions of restricted access to nature and environment in case of a lockdown. Moreover, an urgent issue of global development is ecology and environment protection. Combining socio-economic and ecologic priorities of public development, we have analysed the prospects for further development of ecological tourism as a trend of domestic tourism at the national level. Special losses due to the containment measures are suffered by the countries which had the highest fraction of income from tourism in the structure of the national GDP. Thus, the potential of these countries in terms of prospects for ecotourism development was determined. The geographical location of ecotourism destination was analysed. The analyse shows that these countries can develop and propose attractive for tourists offers of ecotourism in the domestic tourism market. To ensure their promotion, the elements have been identified and an algorithm for the public marketing of domestic ecological tourism offers has been developed.
\end{abstract}

\section{Introduction}

As of today the travel industry is at a low ebb because of the quarantine restrictions. The first essential obstacle to the travel industry development is border closure for international tourism by the majority of the countries in the world. The second factor is the reduction of public income level due to the economic crises caused by the shutdown of a number of enterprises and the actual lockout of the service sector in many countries worldwide. On the other side, an important aspect of understanding of the prospects for the travel industry development is an analysis of trends of harmonic co-existence of human and nature. After

\footnotetext{
Corresponding author: ugodnikova16@gmail.com
} 
all, analysing the man-made impact of the rapid development of tourism on the environment, we can determine its threat to the sustainable development of the planet. Therefore, it is reasonable to determine the prospects for the development of ecological tourism as an element of sustainable development of mankind, which becomes especially urgent in the context of quarantine restrictions and increased demand of the world population for staying and having rest outdoors. Eco-tourism during the pre-quarantine period has been actively developing, and by 2019 could cover over $10 \%$ of the global tourism market. During the pandemic, the development of the tourism industry has decreased significantly, so the number of tourist arrivals in the world by the end of 2020 will fall by $70-80 \%$ in comparison to 2019 , and the losses of the global tourism industry will amount to more than 400 billion USD [1]. These negative trends make tourism market searching for new forms of rendering tourism services. Moreover, travel industry plays an important socio-economic role. Especially in those countries where the development of tourism has an essential impact of the national GDPs, for example, Spain, France, Portugal, Mexica, Iceland etc. [2]. Tourism development rate slowdown in these countries results in the significant reduction of national and regional budget revenue, reduction of social expenditures and growth of unemployment since good many of population is involved precisely in the travel industry. In particular, according to the World Tourism Organization in 2019 prior to the quarantine, one in ten people of our planet worked in the travel industry. Also, it is important to emphasize the development of downstream industries of the national economy which are closely related to tourism, such as hotels and restaurants, transport, communications, construction, trade etc. These sectors of the national economy also have an essential impact on socio-economic development. Therefore, it is reasonable to consider the problem of tourism development taking into account the current challenges of a global nature to ensure sustainable socio-economic and environmental development at the global level.

\section{Analysis of the latest researches and publications}

The travel industry because of its important role in socio-economic development at the global and national level drew the attention of many foreign and domestic scientists. The work of international organization aimed at the support of efficient travel industry development, determination of main trends and tendencies of the industry, development and introduction of mechanisms efficient tourism management in the global and local markets, all this is very important. Issues related to the tourism development at the global level are considered by the World Tourism Organization which is a structural subdivision of the Organization of the United Nations [1]. In addition to the issues of the economic development of tourism, the Organisation for Economic Co-operation and Development [2] is involved in the analysis and estimation of state and trends of economic development according to certain sectors of the national economy. Issues related to ecological tourism development are considered in the works of the scientists as follows: Wang C., Lim S., Tay Z. [3], Rimal, B. [4], Gong, X.; Zhu,W.C., and Liu, S. [5], Kyrkilis, G.; Chaloulakou, A.; and Kassomenos, P. A. [6], Xu, K.; Cui, K.; Young, L.H.; Wang, Y.F.; Hsieh, Y.K.; Wan, S.; and Zhang, J. [7] and other authors. The scientists studied issues of a harmonic combination of the travel industry economic development processes and minimization of the technogenic impact of tourists and tourism infrastructure on the ecology of the area. Global challenges related to the impact of the consequences of the pandemic and global environmental changes on tourism development make researchers searching for ways of implementation of qualitative transformations to rationally respond to new processes and threats. 


\section{Purposes and objectives}

The issue of ecotourism development is extremely urgent, so the study aims to find public marketing mechanisms focused on the development of ecotourism as a form of overcoming global challenges for the industry.

According to the purpose of the paper, the following tasks were performed:

-the concept of ecological tourism and its features were defined,

-the geography of ecological tourism distribution and its coincidence with the leading tourist centres of the world was analysed,

-global challenges for the travel industry and the risks of their occurrence were outlined,

-an algorithm of public marketing of ecological tourism development processes at the national and global level was proposed.

\section{Statement of basic materials}

The first step in understanding the concept of ecological tourism is to determine its consistency and complexity. Analysing the structural elements we can interpret the complexity of this concept. Among them, it is advisable to highlight the environmental and socio-economic components. The ecological component consists in the concept of ecosystem which was first introduced by the scientist, researcher of environmental problems A. Tensley in 1935 [3]. According to the ecologist, the concept of an ecosystem is a set of components of living and inanimate nature, between which there is an energy exchange due to which it is possible to create the conditions necessary to maintain life [4]. That is, it is advisable to include the concept of biocenosis (the totality of all living organisms) and biotope (the territory of these living organisms) in the composition of the ecosystem [5]. So, the ecological side of ecotourism is associated with wildlife and the environment. With the development of mankind, technology and man-made impacts, the concept of an artificial ecosystem was generated. Schematically, the complex of concepts of an artificial and natural ecosystem can be represented as follows - Fig. 1.

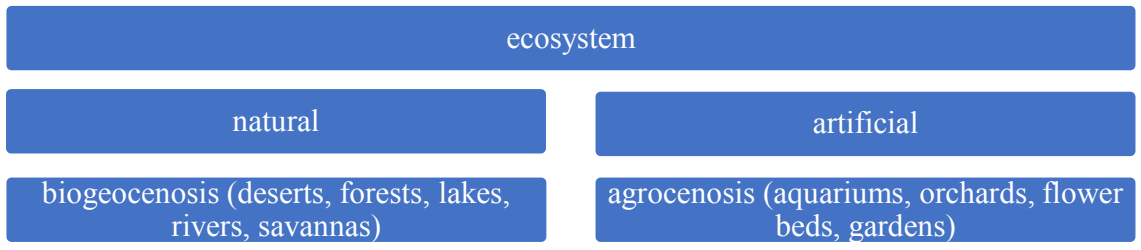

Fig. 1. Concept of Ecosystem and its Structure [6].

The first peculiarity of artificial ecosystems is as follows: all artificial ecosystems are heterotrophic, in other words, they consume ready-to-eat food. Let us consider, for example, a city is one of the biggest artificial ecosystems. The flow of the artificially created energy as pipeline, electricity, food) plays a major role. At the same time, such ecosystems are characterized by a high emission of toxic substances. In other words, those substances which in a natural ecosystem in the future will serve for the production of organic ones, in an artificial one often become useless. [6].

So, analyzing the ecological aspect of the ecotourism development, it is reasonable to note that ecological tourism is focused precisely on the human and natural ecosystems 
harmonious co-existence, reducing the need for the generation of artificial ecosystems with their irrational consumption and high emission of toxic substances.

Another aspect of ecological tourism development is socio-economic factors. Analysing theoretical approaches to the definition of ecological tourism we would like to emphasize that besides the immediate visiting nature-made objects ecotourism supposes dipping into the local atmosphere where tourism is with its ethnic local charm. Accordingly, an important element of ecotourism is familiarizing tourists with ethnographic peculiarities of a certain area [7]. Therefore, people develop broad-based knowledge concerning the peoples of the world, their customs, mentality and so on. Such broad-based knowledge promotes the formation of tolerance and patience for different cultures and nationalities. Also, ethnic local charm provides for the involvement of the local population in the presentation of their own territory, increasing the level of social development, reducing unemployment and improving the material situation of the local population $[8,9]$.

Therefore, ecological tourism promotes solving many global problems, namely, environment pollution, social inequity, intolerance, irrational use of resources and other global problems of stable development of mankind.

In the context of quarantine measures and restricted movement of population because of the pandemic, the problems of interaction between human and nature acquire a particular urgency. On one hand, people's staying in quarantine reduces the technogenic impact on the environment. This data can be confirmed by the shooting from a satellite showing the level of pollution of some territories before the pandemic and during the lockout - Fig. 2

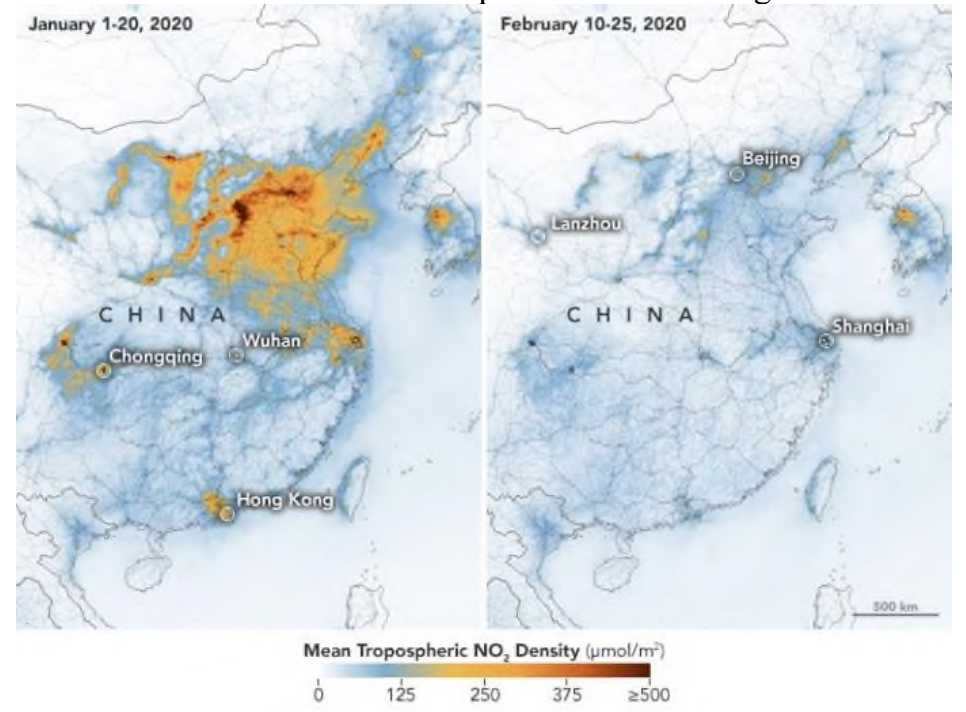

Fig. 2. Pollution Degree of PRC's Atmosphere before Pandemic and After the Quarantine Measures.

According to the data of shooting from a satellite, it is obvious that air pollution in the most polluted areas of the People's Republic of China (the country with the biggest level of industrial production), during the quarantine measures was reduced to zero rates.

However, it should be noted that economic losses due to Coronavirus pandemic are essential. In particular, the travel industry in 2020 according to the experts' forecasts will suffer losses over 400 billion USD, and a number of people who can become unemployed is over 100 million $[1,2]$. These are the significant negative consequences of the pandemic.

In summary, the quarantine restrictions which significantly influenced the travel industry have a positive impact on the ecology development. That is why, it is reasonable to develop a marketing strategy for promoting new tourist product, namely, ecological tourism 
as an alternation to tourism with technogenic pollution of the environment. The positive point shall be considered the limitation of human staying outdoors during the quarantine; thus, proposals of ecological tourism will have high demand and urgency. Let us try to compare prospective opportunities for the development of tourism in the countries where tourism market suffered a lot because of the quarantine restrictions - Table 1 .

Table 1. Analysis of the Countries with the Biggest Losses in the Travel Industry because of the Pandemic.

\begin{tabular}{|l|l|c|c|}
\hline Country & $\begin{array}{l}\text { Number of tourist arrivals } \\
\text { in } 2019\end{array}$ & $\begin{array}{l}\text { \% in GDP structure } \\
\text { of travel industry }\end{array}$ & $\begin{array}{l}\text { Drop in income from travel } \\
\text { industry, 2020 }\end{array}$ \\
\hline Spain & 82 millions of tourists & 11,1 & almost $80 \%$ \\
\hline France & 90 millions of tourists & 7,1 & over $75 \%$ \\
\hline Portugal & 73 millions of tourists & 9,2 & over $75 \%$ \\
\hline Greece & 33 millions of tourists & 22 & almost $80 \%$ \\
\hline Italy & 58,3 millions of tourists & 5,7 & almost $80 \%$ \\
\hline Turkey & 50,2 million of tourists & 5,5 & almost $80 \%$ \\
\hline
\end{tabular}

Therefore, reduction of tourist flows will have an essential impact on GDP and economic development of the analysed countries, having reduced their incomes by 3 to $22 \%$, that will affect population social security.

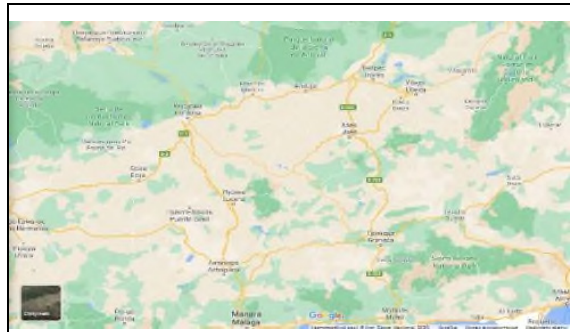

Spain, national natural parks of the south

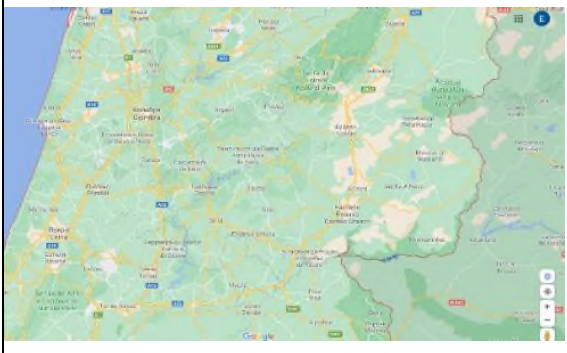

Portugal, national natural parks of the north

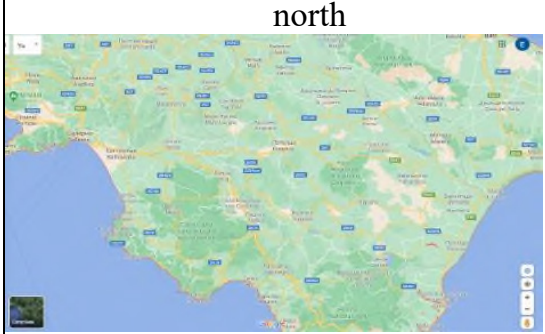

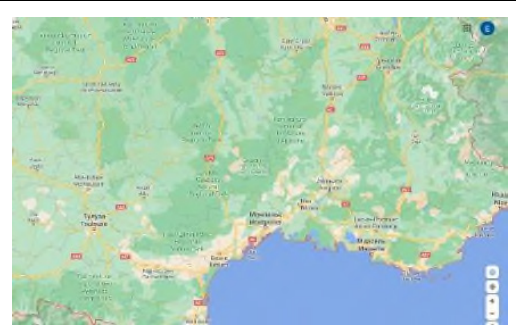

France, national natural parks of the south

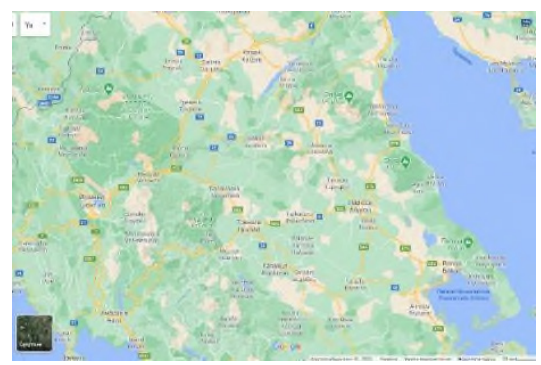

Greece, national natural parks of the coast

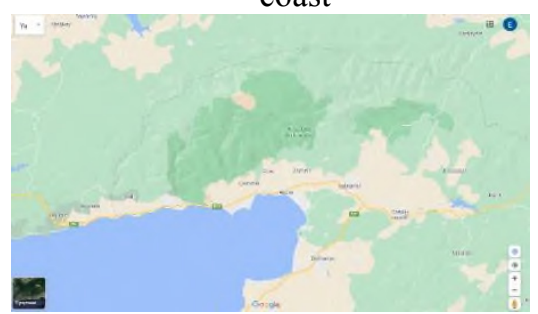


Italy, national natural parks of the coast Turkey, the national nature park of the Mediterranean coast

Fig. 2. Geographical Position of Ecological Tourism Objects.

To avoid the socio-economic crisis the countries who suffered most because of the quarantine measures taking into account restrictions for the travel sector development are proposed to develop ecological tourism public marketing as an element of domestic tourist product. Let us analyse the available tourist potential of these countries in terms of ecological tourism development, namely, the availability of national natural parks and landscape protection area (Zapovednik) - Fig. 2.

According to the analysis results of the geographical position of ecological tourism objects we have determined that all the countries analysed have a high potential for the development of ecological tourism due to the availability of interesting in terms of travelling natural objects.

The following algorithm of public marketing of these territories is proposed in order to develop domestic ecological tourism as a mechanism of reduction of negative consequences from the pandemic. For this purpose let us determine key elements of public marketing Fig. 3.

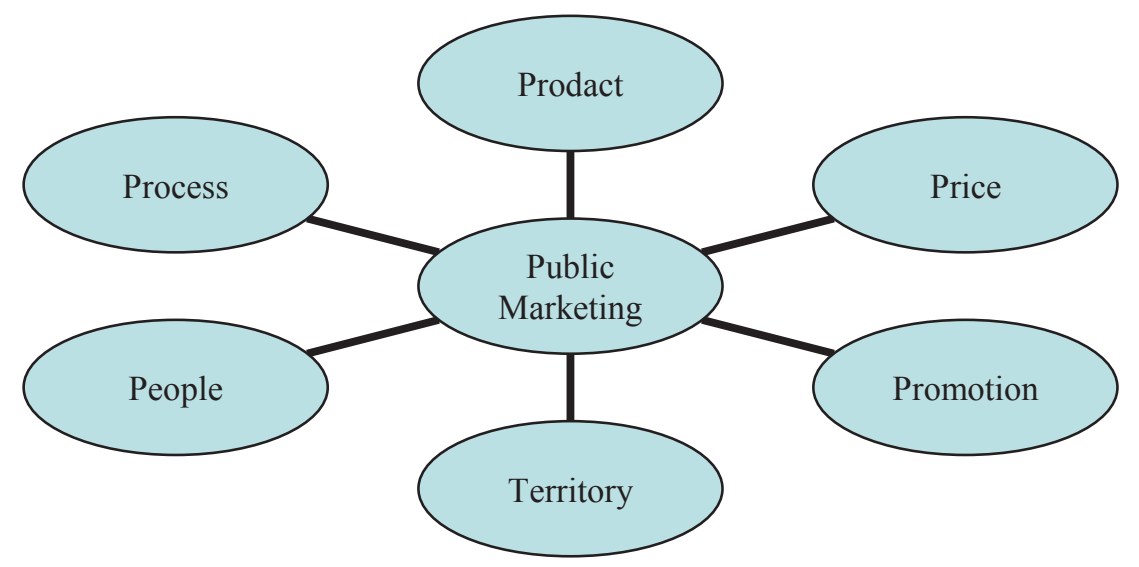

Fig. 3. Elements of Public Marketing.

Therefore, these elements can be grouped in order to implement the following algorithm of the ecological tourism public marketing:

- chosen tourist product - objects of ecological tourism which can be used to promote domestic tourism under the conditions of the high motivation of people to going out into nature because of the quarantine restrictions,

- cost of this trip shall be affordable for various categories of population (from economy class to VIP sector) since these trips because of their locality will cost cheaper than the trips of international tourism, whereas a significant component of these trips was the cost of flights,

- country has to describe ecological tourism as preferential, to ensure the creation of a positive image of territories which can become potentially tourist centres of ecological tourism,

- development of ecological tourism will promote the development of territories in terms of nature conservation (since this is one of the priorities of ecological tourism), as well as socioeconomically (because ecological tourism defines opportunities of local population to ensure socio-economic development), 
- local population obtains additional opportunities to receive income, create new jobs and promote own ethnic local charm, customs and national traditions,

- processes of ecological tourism development promote solving global problems of stable development: rational nature and resources use, reduction of environment pollution degree, combating climate change, tolerance, equity and peace creation.

Therefore, issue related to the ecological tourism public marketing as a tourist product of domestic market can defined as a top-priority task to overcome the consequences of socio-economic crisis during the pandemic.

\section{Conclusions}

The paper analysed the concept of ecological tourism. It is found out that ecological tourism is a basis for the formation of conditions for harmonic co-existence of human and nature since this kind of tourism is related immediately to people's visiting natural ecosystems, that reducing the role of artificial ecosystems. Artificial ecosystems are heterotrophs, that is why, they are a basis for the formation of a system of irrational consumption; moreover, they emit many polluting substances into the atmosphere. Economic and social components of ecological tourism development were analysed. It is determined that ecological tourism is a basis for the generation of socio-economic development of the local population since in its specific character it bears local nature. Reduction of incomes and tourist arrivals in the travel industry is defined as a global challenge of Coronavirus pandemic. Special losses due to the containment measures are suffered by the countries which had the highest fraction of income from tourism in the structure of the national GDP. Another global challenge is problems of ecological nature related to the technogenic impact on the environment. Therefore, it is determined that it is quite urgent to search for mechanisms of tourism development under the conditions of quarantine measures which will not be harmful to the environment. While solving this problem, it was found out how to develop ecological tourism in the domestic tourism market. To ensure the development of national ecological tourism we have determined elements and developed algorithm of public marketing measures implementation which could become objects of ecological tourism.

\section{References}

1. World Tourism Organization. Official website. Electronic resource. - Access mode: http://www2.unwto.org/en

2. Pre-OECD Ministerial Council Meeting Talks - Where are we Today and What's Next? Official website Organisation for Economic Co-operation and Development. - Access mode: http://video.oecd.org/7072/or/Pre-OECD-Ministerial-Council-Meeting-TalksWhere-are-we-Today-and-What-s-Next-.html

3. Leow B.T., Tan H.K. Technology-Driven Sustainable Aquaculture for Eco-tourism. In: Wang C., Lim S., Tay Z. (eds) WCFS2019. Lecture Notes in Civil Engineering, 41 (2020) Springer, Singapore. https://doi.org/10.1007/978-981-13-8743-2_11

4. Rimal, B. Spatiotemporal dynamics of land use pattern response to urbanization in Biratnagar SubMetropolitan City, Nepal, IRACST, 2 (1) (2012)

5. Gong, X.; Zhu,W.C., and Liu, S., The strategy of eco-agriculture economic development along the coast based on improving the rural eco-tourism environment. In: Guido Aldana, P.A. and Kantamaneni, K. (eds.), Advances in Water Resources, 
Coastal Management, and Marine Science Technology. Journal of Coastal Research 104, 652-655 (2020) Coconut Creek (Florida), ISSN 0749-0208.

6. Kyrkilis, G.; Chaloulakou, A.; and Kassomenos, P. A. Development of an aggregate air quality index for an urban Mediterranean agglomeration: relation to potential health effects. Environment International, 33(5), 670-676 (2007)

7. Xu, K.; Cui, K.; Young, L.H.; Wang, Y.F.; Hsieh, Y.K.; Wan, S.; and Zhang, J. Air Quality Index, Indicatory Air Pollutants and Impact of COVID19 Event on the Air Quality near Central China. Aerosol and Air Quality Research, 20, 1204-1221 (2020)

8. Zablotskyi V.V. Legislative supply of public administration of development potential of services management as the element of socio-economic transformations, V. V. Zablotskyi, O. Y. Palant, O. A. Diegtiar, O. I. Uhodnikova, 2, 25 (2018) The socialhumanitarian context of transformational finance-economical processes

9. Suhaimi, N.F.; Jalaludin, J.; and Latif, M. T. Demystifying a possible relationship between COVID-19, air quality and meteorological factors: evidence from Kuala Lumpur, Malaysia. Aerosol and Air Quality Research, 20, 1520-1529 (2020) 